\title{
Political, Socio-Cultural, Economic and Trade Relations between the USSR and Turkey in 1945-1960
}

\author{
Almira Rubisovna Shaidullina ${ }^{1}$ \\ ${ }^{1}$ Kazan Federal University, Kazan, Russia \\ Correspondence: Almira Rubisovna Shaidullina, Kazan Federal University, Kremlyovskaya Street 18, Kazan, \\ 420008, Russia. E-mail: almira-djl@mail.ru
}

Received: January 19, 2014

Accepted: February 22, 2015 Online Published: March 25, 2015

doi:10.5539/res.v7n5p131

URL: http://dx.doi.org/10.5539/res.v7n5p131

\begin{abstract}
Relevance of the research problem is due to the fact that Russia's relations with one of its nearest neighbors-Turkey is an important element of Russian foreign policy strategy, and the basis for cooperation between the two countries was the coincidence of their common goals, namely the providing of security zone of the Black sea Straits which were essential for the interests of both the USSR and Turkey. The purpose of the article is to identify the political, socio-cultural, trade and economic relations between USSR and Turkey in the period from 1945 till1960, which are based on the analysis of the sources and literature. In this regard, the paper investigates the background of the Soviet-Turkish cooperation, studies political relations between the USSR and Turkey in the years 1945-1960; analyzes the Soviet-Turkish trade and economic relations, as well as takes into consideration the cultural relations between the Soviet Union and Turkey in the period from 1945 till 1960 years. The results of this paper can be used in general works on the history of Turkey preparation, as well as in the preparation of courses for historical faculties of higher educational institutions of professional education.
\end{abstract}

Keywords: diplomacy, international relations, Soviet-Turkish relations, political relations, economical external relations

\section{Introduction}

Diplomatic history of the postwar period is the subject of research for many domestic and foreign scientists. These studies are focused on the study of the relations of the USSR with the neighboring countries, where Turkey also plays an important role.

In recent years diplomatic, political, economic, cultural and trade ties with Turkey, which occupies an increasingly prominent place among Russian business partners are intensified. Essentially important role was always given by Turkey to foreign economic relations, which took the main load in the development of its economy. At all stages, except for the war and postwar time periods, one of the main business partners of Turkey was Soviet Russia, the USSR and the Russian Federation.

The basis for cooperation between the two countries was the coincidence of common goals, such as the security zone providing of the Black sea Straits that are essential for the interests of both the USSR and Turkey (Babintsev 1977; Galiakbarova, 2006; Kuznetsova 1961; Shemyakin, 2003; Smirnov, 1972). Thus the addressing to this problem is of particular importance as Russia's relations with one of its nearest neighbors-Turkey is an important element of Russian foreign policy strategy.

In this context, it seems highly relevant to follow the development of bilateral political, trade-economic and cultural relations and to analyze their role in the politics and economy of both countries, and their significance for Russia and Turkey people mutual rapprochement.

\section{Methodological Framework}

\subsection{Theoretical and Empirical Methods}

The theoretic-methodological ground of the study was based on the principle of historicism, involving the study of any phenomenon in the specific historical conditions and relationships, identifying its historical perspective, consideration of the events and phenomena in the unity of past, present, and future (Kalimullin, 2014, 2015). In accordance with this principle the historical process is taken into consideration as natural, targeted developing 
and allowing the probability of qualitatively new structures and systems emergency (Kalimullin, 2015).

\subsection{Sources}

It should be noted that historian who studies this topic, can open favorable opportunities of many published documentary materials using. During the preparation of this article a wide range of published documents was reviewed, which can be divided into two groupsby their origin and functional purpose. The first group is specially prepared and implemented by the Commission for the publication of diplomatic documents as a Annals of USSR foreign policy (Annals of USSR foreign policy, 1983), as well as documents of the Ministry of USSR Internal Affairs(Foreign policy of the Soviet Union, 1949-1971), a number of official publications, which only on Soviet-Turkish relations questions contain much published materials, such as diplomatic correspondence, the results of the negotiations and discussions of the two countries officials, notes, memoranda. The second group of sources consists of materials of the United Nations Organization (United Nations. Official records of the General Assembly, 1956-1957).and its specialized agencies in the field of education, science and culture (UNESCO. Records of the General Conference, 1968). These documents allow us to examine in detail the cultural relations between the considered countries.

\section{Results}

Discussed questions of the history, politics and Economics of these countries by Turkish and Russian scientists, are undeniable in scientific and practical significance. Personal contacts allow parties of both countries to get to know and better understand each other, to share the accumulated knowledge, to share scientific achievements. The study of the history of politics and the economy of Turkey is immersion in the history of the spiritual and material activity not only of Turkish society, but also its familiarity with the history of relations with Russia.

\subsection{Prerequisites of Soviet-Turkish Cooperation}

In the context of efforts that were undertaken by the Soviet Union which were directed to radical restoration of relations with neighboring Turkey and controversial and unresolved questions elimination, the USSR diplomatic notes of August 7 and September 24, 1946 to Turkish Republic government on the question of the Straits should be taken into consideration, and this was the very document which was the basic one between the USSR and Turkey in the post-war period. Later, in the 50s Moscow announced that it hadn't any territorial ambitions to Turkey and refused from the five USSR requirements on Black sea Straits which were launched in 1946.

\subsection{Political Relations between the USSR and Turkey}

The postwar period is characterized as the deterioration of relations between the considered countries, and the fact that Turkey hadn't accept the proposals of the Soviet Union on the Straits, and then Turkey's membership in NATO facilitated it. However, already in the late 50s we observed positive changes in wide circles of the Turkish public, need to restore the international political climate. With the approval were met the perceived impending changes on the world stage, when the tendency to discharge more and more prevailed in international relations.

\subsection{The Soviet-Turkish Trade and Economic Relations}

The orientation of Turkey on the imperialist powers, especially the USA, has led to a drastic violation of the traditionally established Soviet-Turkish trade and economic relations in the postwar period. As for the revival of the Soviet-Turkish trade after world war II, it refers to the mid of 50-ies. In 1954, the trade turnover between the two countries reached 8 million rubles. Late in 50s, the Soviet Union, taking care of the recovery of economic cooperation, gave Turkey a loan in the amount of 3.4 million rubles for a period of three years. It should be noted that positive experience in economic development of the USSR had a certain effect on the formation of new principles in economic policy of Turkey.

\subsection{Soviet-Turkish Relations in the Field of Culture}

Review of Soviet-Turkish relations in the field of culture during the period from 1945 to 1960, allowed to reveal that in 1945-1947 contacts between the scientific institutions of the USSR and Turkey, the exchange of their publications had taken place. All the possible visits of the Ministers of health, as well as contacts between social scientists of both countries carried out. 50-60-ies were in fact the period of the emergence and development of tourist forms of interaction. An important role belongedto meeting in Ankara between the delegations of the foreign tourism department under the USSR Council of Ministers and the Ministry of tourism and information of Turkey.

Thus, we can conclude that, in general, in the years 1945-1960 in the relations between the USSR and Turkey dominated the trend towards cooling of relations, however, towards the end of the 50s, we see theserelationships restoring although the process was long enough. 


\section{Discussions}

Various aspects of relations between the USSR and Turkey in the period under review were studied in some extent by Volkov (1978), Hasratyan (1963), Guseynov (1981), Grishin (2000), Bailey (1977), Kerim-Zade (1978), Kuznetsova (1961), Swierchewskaya (1983), Smirnov (1972), Starchenkov (1981), Urazova (1974), Miller (1965), Moiseev (1983), Dudzinskaya (1978), Babaev (1975), Potsveriya (1976), which contains veryrich material on economic and political issues. The same significance has investigations of Rosaliev (1978), Sarkisyan (1978), published in 60-70-ies of XX century, which contains a large amount of factual material on the economic and political history of Turkey in the period under the review.

A particular interest can be given to the works of Turkish authors such as Hikmet (1957) and Kaprat Kemal (1973). The authors paid their attention to the internal policy of the Turkey republic, and Turkey's relations with other countries. As for the Turkish official publications sources such as speeches of presidents and Prime Ministers of the Republic, the protocols of the meetings of the Grand National Assembly of Turkey, government statements, the texts of international treaties and agreements, policy program documents of political parties and trade unions, various statistical materials were taken into consideration.

A complicated set of international problems, including those that were related to the policy of the Western countries in Turkey is reflected in the multi-volume official publications, which were made in the USA, England, France, West Germany. However, a clear accent and a desire to present the events inits own advantage - primarily is characterized by these documents. Besides, some of them (we are talking mainly about the German captured material) is given predominantly in different ways - it all depends on which Western countries they were published.

It's useless to look for any materials that characterize active and consistent struggle of Soviet diplomacy for peace and collective security on the eve of the war and in the postwar period, as well as the persistent efforts of the USSR, aimed at the development of business cooperation with many countries, including Turkeyin the above-mentioned publications of western countries. On the contrary, peace-loving foreign policy of the Soviet Union is presented in a distorted, falsified, often erected malicious slander on the world's first socialist state.

However, a critical approach to diplomatic materials, published in the West, comparing them with other sources allows to get useful information. So, on the eve of the second world war, the governments of England and France have provided some Eastern European and Balkan countries, including Turkey, the so-called "guarantees" in case of aggression by Nazi Germany. But, obstacles and conditions nominated for the ways of their realization, in fact, negated the possibility of their implementation. On some aspects of Soviet-Turkish relations during the postwar period, as well as relations in the field of culture, materials of the United Nations and its specialized agencies in the field of education, science and culture (UNESCO) shed light (UNESCO. Records of the General Conference, 1968).

The development of this perspective also provides for the use of the materials in foreign archives and primarily Turkish, although the latter still remain inaccessible for other researchers.

An important group of sources are memoirs, political biographies, diaries, belonging to the Soviet diplomats, journalists, military leaders, scientists, technologists and culture workers. Being direct witnesses to and participants in many memorable events, they are based on personal observations and recreate a vivid picture of the Communist party and the Soviet states activities, aimed at strengthening of global peace and security against the threat of war and for broad international cooperation .

In foreign memoir literature, where usually about Soviet-Turkish relations in 1945-1960 is spoken, we can distinguish at least three directions. The first are the publications in which the authors, from the standpoint of the Marxist-Leninist world view, evaluate the activities of Soviet diplomacy in relation to the East countries, particularly Turkey. Second - memories of those who seek more or less objectively talk about the vision, kindly demonstrate the USSR and its peaceful foreign policy. And finally, memoirs of the third direction is not free from the lies and distortions of reality, but they often contain deliberate falsification of the historical truth.

\section{Conclusion}

Analysis of Soviet-Turkish relations, their directions and trends for nearly four decades, of difficult, contradictory, but peaceful development allowed to do the following main conclusions:

1) Relations of both countries were built on the unshakable principles of peaceful coexistence of states with different social systems on the basis of full equality, respect for sovereignty, territorial integrity and noninterference in the internal affairs of each other. 
2) Carrying out its international mission of support oppressed peoples and countries of the East, the Soviet Union, including the Ukrainian SSR, has helped the Turkish Republic in strengthening its economic independence, the revival and development of culture, science and professionals training.

3) The USSR demonstrated the noble character of the Lenin peace-loving foreign policy towards neighboring Turkey at any critical point in its history. Throughout time, the Soviet side undertook everything that was in its abilities to prevent further deterioration of relations with its neighbor.

4) In spite of the intensification of the internal reactions and unceremoniously push of some countries the positive trend in the foreign policy of Turkey in the neighborhood with the USSR, however, was breaking through. It can reasonably be argued that already in the end of the $50 \mathrm{~s}$, this trend prevailed and brought tangible benefits.

5) It is necessary to emphasize the role and importance of socio-economic factors in the foreign policy forming process of Turkey, the increased influence of the public of this country on the behavior line of its ruling circles. In this regard, the special relevance belongs to indication said by V. I. Lenin that "to select "foreign policy" from general politics or especially to oppose external and internal policy is fundamentally wrong, non-Marxist, non-scientific thought." Indeed, social and class development of Turkish society, the evolution of the national bourgeoisie, the action of which was characterized by reactionary direction, were the main factors behind the change in the foreign policy of this country at the turn of the 40-ies. Elimination from the political arena in the result of a state coup on May 27, I960 of those representatives of major Turkish bourgeoisie, who most meekly followed the Pro-American course, created the necessary prerequisites for the planned subsequent normalization of Turkey's relations with its great neighbor in the North-USSR.

We can easily recognize the fact that the Soviet-Turkish relations, friendship until 1954, was in the process of deterioration. In 50, between Moscow and Ankara there was tensions, despite of a number of steps on the part of Soviet diplomacy in attempts to weaken the tension after the death of Stalin. On May 30, 1953, Moscow announced about the absence of territorial ambitions to Turkey (indirectly presented to Ankara through the Soviet press in December 1945) and about the refusal from five requirements of the USSR on the black sea Straits, launched in 1946. Turkish politicians and historians don't like to mention the USSR renounced their ambitions.

The positive development of the Soviet-Turkish relations, as in the prewar time, and in the late 50s is remarkable and instructive factor. Two States belonging to different social systems, and in the postwar period - to warring military alliances, could not only coexist but made mutually advantageous cooperation in the field of foreign economic relations, cultural exchanges, and even in the sphere of political contacts. The accumulated experience of such relationships and cooperation is very fruitfully was used by Soviet foreign policy. "We are ready to further development of good relations with our neighbor Turkey"- was stated in the report of the CPSU Central Committee to XXVI Congress of the party (Verbatim record of the Soviet Union Communist Party XXVI Congress, 1981).

\section{Recommendations}

The studied experience can be applied to the continuation and improvement of political, trade, cultural and other relations with Turkey, especially in the framework of the renewed relationship due to open opportunities in the result of recent political events in the Crimea and the opening of an important sea passages in the course of the reunification of the Crimea with Russia.

The results of this paper can be used in the preparation of general works on the history of Turkey, as well as in the preparation of courses for historical faculties, at essays, term papers and dissertations writing on world history, and the history of international relations.

\section{Acknowledgements}

The author is very thankful to the doctor of historical Sciences, Professor, head of Department of International relations and diplomacy from the Institute of international relations, history and Oriental studies at Kazan (Volga region) Federal University Yakov Yakovlevich Grishin for scientific supervisor in this problem studying.

\section{References}

Annals of USSR foreign policy. (1983). Moscow: Politizdat.

Babaev, A. A., \& Nazim, H. (1975). Life and work (p. 380). Moscow: Chapters. ed East. literature publishing house "Nauka".

Babintsev, V. A. (1997). Policies of the great powers in the Balkans and the Middle East (1933-1943) (p. 116). Sverdlovsk. 
Dudzinskaya, E. A. (1978). International scientific relations of Soviet historians (p. 290). Moscow: Nauka.

Gafurov, B. G., \& Miroshnikov, L. I. (1976). Study of the civilizations of Central Asia. In The experience of the international cooperation in UNESCO project (p. 127). Moscow: "Nauka".

Galiakbarova, N. M. (2006). Soviet-Turkish relations in 1939-1941 (Unpublished master's thesis) (p. 215). Ekaterinburg.

Gordlevsky, V. A. (1944). Chekhov in Turkey. Proceedings of the Academy of Sciences of the USSR, 220-227.

Grishin, Y. Y. (2000). Civilizing: The harsh lessons of history (p. 265). Kazan: School.

Grishin, Y. Y. (2010). Dialogue of Civilizations: East-West: Collection of scientific and educational works. Kazan: Kazan State University.

Guseinov, A. A. (1978). Turkish cinema. History and contemporary problems (p. 205). Moscow: Chapters. ed East. literature publishing house "Nauka".

Guseinov, A. A. (1981). Mass media in the political life of Turkey (p. 230). Moscow: Chapters. ed East. literature publishing house "Nauka".

Hasratyan, M. A., \& Moiseev, P. P. (1963). Turkey is waiting for a change. Moscow: Publishing house of the East. literature.

Hikmet, N. (1952). The story of Turkey (p. 103). Moscow: Publishing house of foreign literature.

Hikmet, N. (1957). Selected works, I-II (p. 567). Moscow: Goslitizdat.

Ibrahim-Bailey Hadji Murat. (1977). The collapse of the "Edelweiss" and the middle East (p. 163). The chapters.ed East. literature publishing house "Nauka".

Kalimullin, A. M. (2014). Stages of ecological policy development in the industrial sector of Russia in the second half of the XXth century: Historical perspective. Life Science Journal, 11(8), 492.

Kalimullin, A. M. (2015). Ecological problems of middle Volga in the second half of the XXth century: Historical and ecological analysis of leading industrial regions development. Review of European Studies, $7(1), 86$.

Kalimullin, A. M. (2015).The Historical and Ecological Analysis of Middle Volga Industrial Development in Russia in the Second Half of the XXth Century. Review of European Studies, 7(4), 172-176. http://dx.doi.org/10.5539/res.v7n4p172

Karpat, K. H. (1959). Turkey's Politics: The Transition to a Multi-Party System (p. 522). New Jersey: Princeton University Press.

Karpat, K. H. (1973). Social change and politics in Turkey (p. 304). Leiden.

Kerim-Zadeh, R. I. (1978). Parliament and parliamentarism in Turkey (pp. 26-35). Moscow: Chapters. ed, literature publishing house "Nauka".

Kuznetsova, S. I. (1961). Establishment of Soviet-Turkish relations (p. 85). Moscow: Publishing house of the East.literature.

Miller, A. F. (1965). The Restoration of the Soviet-Turkish friendship: A wish or reality? New time, 4, 6-8.

Miller, A. F. (1948). Essays on the modern history of Turkey (p. 280). Moscow: Edit. of USSR Academy of science.

Moiseyev, P. P. (1983). About the typology of economic development of modern Turkey (pp. 45-65). Moscow: Nauka.

Potskhweria, B. M. (1976). Turkey's Foreign policy after the second world war (p. 306). Moscow: Chapters.ed.literature publishing house "Nauka".

Potskhweria, B. M. (1978). The Main stages of the Soviet-Turkish relations. In Problems of Turkish history (Collection of articles) (pp. 161-171). Moscow: Chapters. ed. E. literature publishing house "Nauka".

Potskhweria, B. M. (1981). Outstanding fighter for the independence of Turkey. Asia and Africa today, 9, 39-41.

Rosaliev, Y. N. (1956). Essays provisions of the industrial proletariat of Turkey after the second world war (p. 208). Moscow: Publishing house of Academy of Sciences of the USSR.

Rosaliev, Y. N. (1980). Economic history of the Turkish Republic (p. 304). Moscow: Chapters. ed. literature publishing house "Nauka". 
Sarkisyan, E. K. (1978). Turkology in Armenia and its development prospects (pp. 72-82). Moscow: Chapters. literature publishing house "Nauka".

Shemyakin, A. (2003). Black Sea straits: History and Contemporary Issues. Transport Law, 4, 44-46.

Smirnov, B. (1972). On the basis of mutual benefit, in the interests of strengthening the economic independence of developing countries (pp. 24-29). Foreign trade.

Starchenkov, G. I. (1981). Workforce of Turkey.Demographic, economic and social aspects (p. 204). Moscow: Chapters. ed. E. literature publishing house "Nauka".

Swierchewskaya, A. K. (1983). Soviet-Turkish cultural relations, 1925-1981 (pp. 60-71). Moscow: Chapters. ed. E. literature publishing house "Nauka", 60-71.

The XXVI Congress of the Communist Party of the Soviet Union. (1981). Verbatim record (p. 129). Moscow.

UNESCO. (1968). Records of the General Conference. Paris.

Urazova, E. I. (1974). Turkey: Problems of financing of economic development (p. 247). Moscow: Chapters. ed. E. literature publishing house "Nauka",

Volkov, V. K. (1978). The Munich agreement and the Balkan countries (p. 327). Moscow: Nauka.

\section{Copyrights}

Copyright for this article is retained by the author(s), with first publication rights granted to the journal. This is an open-access article distributed under the terms and conditions of the Creative Commons Attribution license (http://creativecommons.org/licenses/by/3.0/). 